\title{
Developing a curriculum statement based on clinical practice: genetics in primary care
}

\author{
Sarah Burke, Melissa Martyn, Anna Stone, Catherine Bennett, Hywel Thomas and Peter Farndon
}

\author{
ABSTRACT \\ Background \\ Advances in medical genetics are increasingly being \\ incorporated into clinical management outside \\ specialist genetic services. This study was therefore \\ undertaken to develop learning outcomes in genetics \\ for general practice specialty training, using methods \\ to ensure the knowledge, skills, and attitudes relevant \\ to genetics in primary care were identified.

\section{Aim} \\ To identify key knowledge, skills, and attitudes in \\ genetics and to synthesise these into learning \\ outcomes to assist training in genetics for primary \\ care. \\ Design of study \\ Delphi survey and review by expert group.

\section{Setting} \\ Primary care practices and Regional Genetics Centre in \\ the West Midlands region of the UK.

\section{Method} \\ A modified Delphi survey involved GP trainers, \\ programme directors, and geneticists $(n=60)$. The \\ results, along with results from a survey of GP \\ registrars, were reviewed by an expert group, which \\ included GPs, geneticists, and educationalists.

\section{Results} \\ Core genetics topics for GPs were identified, \\ prioritised, and developed into competency statements \\ in the style of the curriculum structure of the Royal \\ College of General Practitioners.

\section{Conclusion} \\ The development of the GP curriculum statement \\ Genetics in Primary Care was based on a study of \\ educational needs, incorporating the views of \\ practitioners (GP trainers, programme directors, and \\ registrars) and specialists (clinical geneticists). This \\ inclusive approach has enabled the identification of \\ learning outcomes which directly reflect clinical \\ practice.

\section{Keywords} \\ curriculum; family practice; genetics.
}

\section{INTRODUCTION}

A minimum of 1 in 10 patients seen in primary care is reported to have a disorder with a genetic component. ${ }^{1}$ As advances in understanding of genetics are increasingly influencing clinical management, it is important to identify individuals and families for whom genetic information and testing would be helpful. For instance, genetic testing for single gene disorders such as familial hypercholesterolaemia, and inherited cardiomyopathies or arrhythmias may identify asymptomatic family members who would benefit from prophylactic treatment. Testing for carrier status is available for conditions such as sickle cell anaemia and cystic fibrosis. Taking a family history may identify those families with the highest predisposition to common diseases such as cancer and diabetes; this can influence referral, management, and treatment. Again, genetic testing may be possible to determine those who would benefit from surveillance.

Encouraging the acquisition of appropriate genetics knowledge, skills, and attitudes during training is therefore likely to be of value to GPs providing support and management to patients and

S Burke, $B A$ (Hons), $M A, P h D$, research fellow; H Thomas, BA, MEd, PhD, PGCE, director; Centre for Research in Medical and Dental Education, University of Birmingham. M Martyn, $B A / B S c$ (Hons), PhD, education development officer; C Bennett, $B C h D, M S c, P h D$, education specialist; P Farndon, $M S c, M D$, FRCP, DCH, director, NHS National Genetics Education and Development Centre, Birmingham. A Stone, MRCP, MRCGP, partner, Thornley Street Surgery and GPwSI in Genetics, Wolverhampton Primary Care Trust.

Address for correspondence

Sarah Burke, Centre for Research in Medical and Dental Education, School of Education, The University of Birmingham, Edgbaston, Birmingham, B15 2TT. E-mail: s.e.burke@bham.ac.uk

Submitted: 26 June 2008; Editor's response: 28 August 2008; final acceptance: 23 September 2008.

(c)British Journal of General Practice 2009; 59: 99-103.

DOI: 10.3399/bjgp09X395094 


\section{How this fits in}

GPs have a key role in identifying and supporting patients and families who may benefit from advances in clinical genetics. Acquiring key knowledge, skills, and attitudes during training are important to support this role. Learning outcomes in genetics that are relevant to primary care practice have therefore been identified, firmly grounded in clinical practice, and developed by consensus between GPs and genetic specialists. The learning outcomes are useful not only for specialty trainees but also for established practitioners who wish to update their genetics knowledge and skills. families with, or at risk of, genetic conditions, and to help prepare for future clinical advances.

However, the provision of genetics education has not been able to keep pace with clinical advances in genetics. Studies have shown that GPs feel they lack knowledge and skills relevant to genetics, and therefore lack confidence in handling requests by patients for genetic information. ${ }^{2,3}$ A survey of GP registrars in 2003 found a majority of responders believed genetics was important, but felt underprepared because of low levels of genetic education. ${ }^{4}$ A recent study of people with or at risk of genetic conditions, and parents of children affected by a genetic condition, found that GPs played a vital role in providing ongoing information and support, but there was a need for greater awareness of genetic aspects of conditions. ${ }^{5} \mathrm{~A}$ review of genetics education for UK health professionals in 2002 identified that the need for a genetics curriculum had been particularly articulated by GPs. ${ }^{6}$
In the UK, core learning outcomes and competences in genetics have been identified for nurses, midwives, and health visitors, ${ }^{7}$ medical students, ${ }^{8}$ non-genetics specialist registrars, ${ }^{9}$ and non-genetics healthcare professionals. ${ }^{10}$ This paper describes the development of genetics learning outcomes relevant to primary care practice and how they informed part of a new curriculum for general practice, which sets out the knowledge, competences, clinical, and professional attitudes considered appropriate for a doctor intending to practise in primary care in the UK NHS. ${ }^{11}$

\section{METHOD}

The development of the Genetics in Primary Care curriculum statement occurred in three main phases (Figure 1). In phases 1 and 2, topics and priorities for genetics education were identified using a modified Delphi approach involving GP trainers, GP training programme directors, and genetics consultants. In phase 3 , an expert group of individuals with expertise in primary care, education, and genetics reviewed and developed the survey results into a curriculum for genetics in primary care.

The modified Delphi approach was conducted in the West Midlands region of the UK between March 2003 and January 2005. From 353 GP trainers in the West Midlands, 40 were randomly selected by a computer programme, then contacted by letter and invited to complete either a paper-based or online survey. Ten genetics consultants and $10 \mathrm{GP}$ programme directors were also invited to complete the survey. In the first phase, participants were

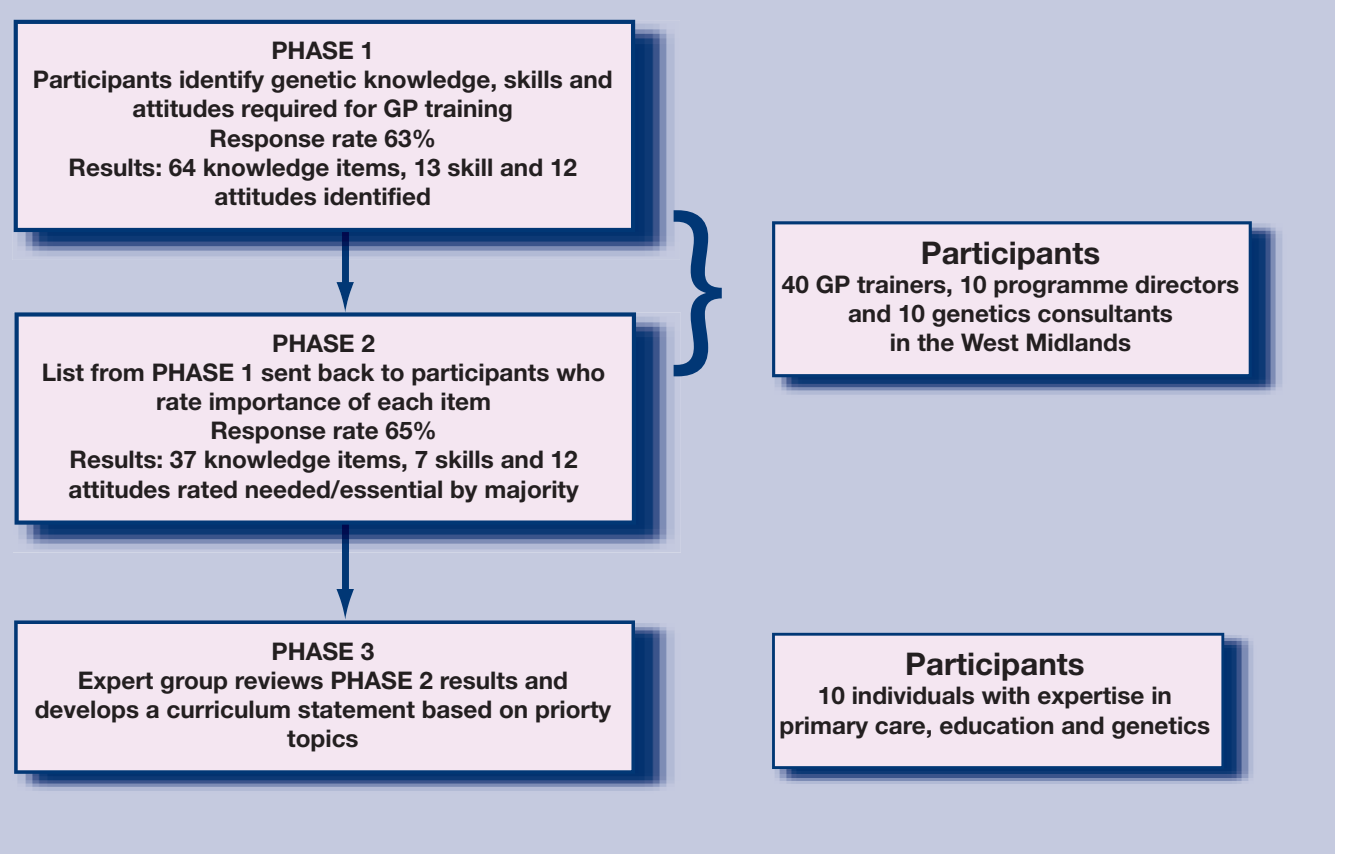


asked, in an open question, to identify topics or areas in genetics that they thought should be included within GP specialty training, based on their clinical experience. The results formed the basis of the second phase, where participants were asked to comment on the list of topics that had been generated and rate each item on a four-point scale (essential for inclusion in the curriculum; needs to be included; useful for inclusion; need not be included). They were also asked to choose the five items of greatest educational priority. Results were analysed using SPSS software (version 11).

\section{RESULTS}

In the first phase of the Delphi process, responses were received from $23 \mathrm{GP}$ trainers, nine GP programme directors, and six genetics consultants, an overall response rate of $63 \%(38 / 60)$. Eight responders did not wish to be involved in the second phase (seven GP trainers and one programme director), and therefore 52 participants were sent the second Delphi questionnaire. Thirtyfour responses were received (18 GP trainers, six programme directors, and 10 geneticists), an overall response rate of $65 \%$.

Responses to the first Delphi survey were collated by two members of the project team (a GP and a geneticist) to remove repetitions and group items under headings, resulting in a draft topic list of 89 items (no items were excluded at this stage). The 89 items were presented in the second-round questionnaire. In response, 37/64 knowledge items, $7 / 13$ skills, and all 12 attitudes were identified as 'essential' or 'needs to be included in the curriculum' by more than $50 \%$ of responders. Particularly high percentages (over $85 \%$ ) rated the following topics as essential or needed: understanding when and how to make a referral to clinical genetics; guidelines for referral (familial cancer); recognising the basic patterns of inheritance; identifying families who would benefit from referral to the genetics services; accessing the services of the local genetics centre; and making appropriate referral to genetics clinics. In open comments, trainers noted the need to balance genetics education with other curriculum needs, and to focus on areas important in practice.

The second Delphi survey also asked responders to list in order their top five priorities for the curriculum. The topic listed first was assigned a score of 5 , the second choice 4 , and so on. All scores for each topic were summed to produce an 'importance rating'. The priority topics fell naturally into three themes: identifying patients, clinical management, and communicating genetic information. These mirror the areas where genetics has a current clinical impact in general practice. Figure 2 illustrates these themes and is accompanied by an overview of associated learning outcomes in Box 1.

Participants in the survey also stated that GP specialty trainees should be encouraged to develop knowledge about the management and genetics of certain conditions. Seventeen conditions were identified; these include chromosomal conditions (for

Figure 2. The key themes of the curriculum statement.

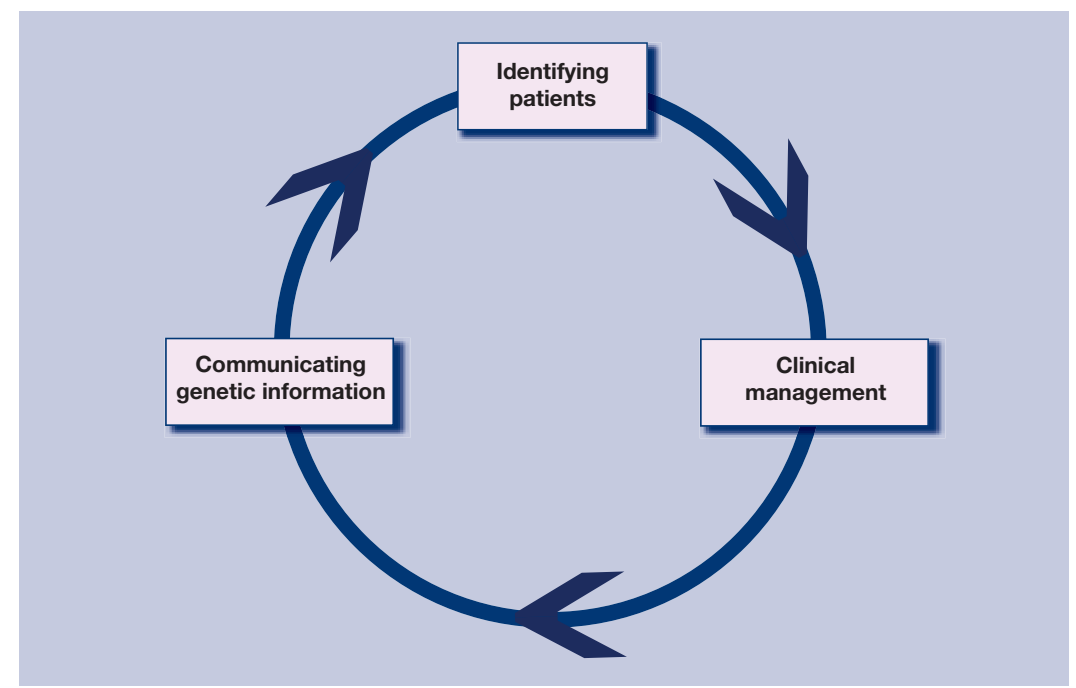

\section{Box 1. The key themes supporting the RCGP curriculum statement Genetics in Primary Care and an overview of the associated learning outcomes.}

Identifying patients with, or at risk of, a genetic condition.

- Knowledge of genetic basis and clinical features of common and/or important conditions.

- Ability to take and interpret family history information.

- Understand how genetic changes may cause disease.

- Recognise patterns of inheritance (single gene, chromosomal, and multifactorial).

- Awareness of genetic implications of antenatal and neonatal screening programmes.

Clinical management of genetic conditions.

- Describe local and national referral and management guidelines for patients with genetic conditions.

- Able to access specialist help and advice from genetic services and refer appropriately.

- Awareness of management options (reassurance, managing uncertainty, reproductive options, preventative measures, and surveillance).

- Able to provide and coordinate patient-centred care including an awareness of patient support groups.

- Awareness of different uses of genetic tests (diagnostic, predictive, and carrier testing) and potential emotional, ethical, legal, and social issues associated with these.

Communicating genetic information.

- Ability to communicate genetic information in an understandable, non-directive manner.

- Appreciate the emotional, ethical, legal, and social impacts of genetic information on patients and their families. 


\section{Box 2. Overarching learning outcomes identified by the expert review group.}

By the end of general practice training the trainee:

- (1) can identify patients with a genetic condition, drawing on a basic understanding of genetics and inheritance patterns;

(2) can manage the healthcare needs of patients with a genetic condition;

- (3) can appropriately refer patients with a genetic condition;

(4) can access relevant information on genetics;

(5) understands the differences between different types of genetic tests, their uses and limitations, and ethical issues associated with genetic testing; and

(6) can discuss genetic information with patients.

example, Down's syndrome), single gene disorders (for example, adult polycystic kidney disease, haemochromatosis, and haemophilia), common disorders with a genetic component (for example, Alzheimer's disease), and familial cancers (breast and bowel). Recommended core knowledge about genetic science included DNA as the genetic material, how mutations and variants contribute to human disease, and how to recognise patterns of inheritance.

In September 2005, an expert review group called together by the NHS National Genetics Education and Development Centre (NGEDC) used the findings, as well as those from a survey of GP registrars, ${ }^{4}$ to develop six overarching learning outcomes, based on the individual items identified in the survey (Box 2). These learning outcomes for genetics in primary care build on those for medical students, ${ }^{8}$ and are complementary to those for non-genetics specialist registrars. ${ }^{9}$ Learning outcome 1 relates to the theme of identifying patients, learning outcomes 2, 3, 4, and 5 relate to the theme of clinical management, and learning outcome 6 relates to the theme of communicating genetic information. The individual items identified in the survey were assigned to each of these overarching learning outcomes, giving more detail for learning and teaching.

The new curriculum for the Royal College of General Practitioners presents learning outcomes in a format that re-enforces the characteristics of general practice. There are six domains (primary care management, person-centred care, specific problem-solving skills, a comprehensive approach, community orientation, and a holistic approach) as well as contextual, attitudinal, and scientific aspects. ${ }^{12}$ The curriculum items were therefore assigned to these categories. For instance, 'demonstrate how to take and interpret a family history' was placed under the category of 'specific problem-solving skills'. The full curriculum statement is available on the Royal College of General Practitioners' website. ${ }^{11}$

\section{DISCUSSION}

\section{Summary of main findings}

In order to develop a curriculum for GP specialty registrars that is grounded in clinical practice, a modified Delphi process was conducted with GP trainers, programme directors, and geneticists. Topics were identified, prioritised, and assigned to three themes of genetics in clinical practice which emerged: identifying patients, clinical management, and communicating genetic information.

\section{Strengths and limitations of the study}

The curriculum development approach outlined in this paper was strengthened by the involvement of stakeholders with a range of roles. To ensure relevance to general practice and to incorporate the experience of trainers and practising GPs, the participant sample was biased in favour of GP trainers, who formed two-thirds of the sample (40/60). The inclusion of geneticists ensured that specialist knowledge and views were also reflected. This was particularly important in the first Delphi process, when geneticists generated more items per responder (9.7) than GP trainers (5.3) and programme directors (5.2), providing a broader list of topics for participants to respond to in the second Delphi process.

The study was conducted in the West Midlands region of the UK and, due to cost and time restrictions, only participants from this region were invited to take part. This could be a limitation, as participants from other regions may have different views. However, no regional differences were identified in a similar study to develop learning outcomes for non-genetics specialist registrars, which was UK-wide. ${ }^{9}$ Efforts were also made to reduce sample bias through the random selection of GP trainers using computer software.

The expert group was drawn from the West Midlands, also due to time and funding constraints. However, to reduce the possibility of personal priorities or viewpoints unduly influencing the development of the curriculum statement, the group had members from primary care, education, and genetics.

\section{Comparison with existing literature}

The importance of genetics training for GPs has been widely recognised. ${ }^{13-15}$ However, research to inform the development of a curriculum for such education is very limited.

In the US, core competencies have been identified for health professionals from all disciplines, ${ }^{16}$ and for family practice, ${ }^{17}$ produced by specialist groups. In Australia, genetics has also been included in the curriculum for Australian 
general practice..$^{18}$ Where genetic knowledge and skills have been previously identified for primary care in the UK, they have been compiled through review of the published literature by a specialist group. ${ }^{19,20}$ A review of education in genetics for health professionals highlighted the importance of education based on an assessment of educational needs, encompassing both what professionals say they need and what experts think they need. ${ }^{6}$ The research outlined in this paper attempts to meet that challenge: to develop a curriculum statement for genetics in primary care based on the views and priorities of both generalists and specialists.

\section{Implications for future research and clinical practice}

This study has demonstrated a curriculum development process that has identified priority topics and focused on areas most relevant to clinical practice. Such prioritisation of topics is particularly important given the current demands on specialty learning time and the need to balance different areas of the curriculum. ${ }^{4}$ The study has also shown how consensus methods, such as the Delphi process, can be used to draw on the expertise of a range of stakeholders and integrate their different viewpoints.

This study has identified priority topics for genetics education in primary care in the UK, focusing on clinical applications that can be incorporated into practice now to make a difference to patient care. The curriculum statement will be useful not only for GP trainees, but also for practising GPs who wish to reflect on their own learning needs and address them. The NHS National Genetics Education and Development Centre (www.geneticseducation.nhs. uk) is working with GPs to develop a range of teaching and learning materials, based on the curriculum, which could be used in practice-based teaching, self-directed learning, and formal training sessions.

\section{Funding body}

The Delphi process was funded by the NHS West Midlands Workforce Deanery. The development of a curriculum statement was conducted by the NHS National Genetics Education and Development Centre, which is funded by the Department of Health and Welsh Assembly Government

\section{Ethical approval}

Ethics approval was not required for this educational development activity

\section{Competing interests}

The authors have stated that there are none

\section{Acknowledgements}

We would like to thank all those involved in the Delphi process for their contributions. We particularly thank all those involved in the expert review group. We also thank Liz Potts for her administrative support.

\section{Discuss this article}

Contribute and read comments about this article on the Discussion Forum: http://www.rcgp.org.uk/bjgp-discuss

\section{REFERENCES}

1. Hopkinson I. Clinical context of genetics in primary care. Presentation at: Reality not hype: the new genetics in primary care, Royal College of Physicians, London, 30 Jan 2004. http://www.londonideas.org/internet/events/documents/hunterbookl et.pdf (accessed 11 Dec 2008)

2. Watson EK, Shickle D, Qureshi N, et al. The 'new genetics' and primary care: GPs' views on their role and their educational needs. Fam Pract 1999; 16(4): 420-425.

3. Hayflick SJ, Eiff MP. Will the learners be learned? Genet Med 2002; 4(2): $43-44$.

4. Burke S, Stone A, Bedward J, et al. A 'neglected part of the curriculum' or 'of limited use'? Views on genetics training by nongenetics trainees and implications for delivery. Genet Med 2006; 8(2): $109-5$.

5. Burke S, Bennett C, Bedward J, et al. The experiences and preferences of people receiving genetic information from healthcare professionals. Birmingham: NHS National Genetics Education and Development Centre, 2007.

6. Burton H. Addressing genetics, delivering health. A strategy for advancing the dissemination and application of genetics knowledge throughout our health professions. Cambridge: Public Health Genetics Unit, 2003.

7. Kirk M. Fit for practice in the genetics era: a competence based education framework for nurses, midwives and health visitors. Glamorgan: Genomics Policy Unit, 2003.

8. NHS National Genetics Education and Development Centre. Proposed learning outcomes in genetics for medical students. http://www.geneticseducation.nhs.uk/teaching/downloads/medical_s tudents_LOs.pdf (accessed 19 Dec 2008).

9. Burke S, Martyn M, Thomas H, et al. The development of core learning outcomes relevant to clinical practice: identifying priority areas for genetics education for non-genetics specialist registrars. Clin $\mathrm{Med}$ : in press.

10. NHS National Genetics Education and Development Centre and Skills for Health. Enhancing patient care by genetics in clinical practice. http://www.geneticseducation.nhs.uk/practice/downloads/Competen ce_Framework.pdf (accessed 19 Dec 2008).

11. Farndon P, Martyn M, Stone A, et al. Genetics in primary care. Royal College of General Practitioners Curriculum Statement 6, 2007. http://www.rcgp-

curriculum.org.uk/PDF/curr_6_Genetics_in_Primary_Care.pdf (accessed 11 Dec 2008).

12. Royal College of General Practitioners. Being a general practitioner. Curriculum for Specialty Training for General Practice core statement, 2007. http://www.rcgpcurriculum.org.uk/PDF/curr_1_Curriculum_Statement_Being_a_G P.pdf (accessed 11 Dec 2008).

13. Department of Health. Our inheritance, our future: realising the potential of genetics in the NHS. London: HMSO, 2003.

14. Rafi I, Burton H. Genetics education and the general practitioner. Educ Prim Care 2007; 18(2): 136-139.

15. Hopkins $\mathrm{M}$. Is primary care the right place for genetic diagnosis? $\mathrm{Br} \mathrm{J}$ Gen Pract 2007; 57(542): 750-751.

16. National Coalition for Health Professional Education in Genetics (NCHPEG). Core competencies in genetics essential for health care professionals. http://www.nchpeg.org/core/Core_Comps_English_2007.pdf (accessed 11 Dec 2008).

17. American Academy of Family Physicians (AAFP). Medical genetics: recommended core educational guidelines for family practice residents. 1999. http://www.aafp.org/afp/990700ap/core.html (accessed 14 Oct 2008).

18. Royal Australian College of General Practice (RACGP). Curriculum for Australian general practice. http://www.racgp.org.au/curriculum (accessed 14 Oct 2008).

19. Emery J, Hayflick $S$. The challenge of integrating genetic medicine into primary care. BMJ 2001; 322(7293): 1027-1030.

20. Royal College of General Practitioners. Genetics in primary care: $a$ report from the RCGP North West England Faculty Genetics Group. Occasional Paper 77. London: Royal College of General Practitioners, 1998. 